\title{
Assessment of the role of gabapentin in patients with supratentorial tumours undergoing craniotomy under general anaesthesia: A double-blind randomised study
}

\author{
Rabie Soliman, Gomaa Zohry
}

\begin{abstract}
Background: Gabapentin attenuates the haemodynamics, decreases the catecholamine release and has a neuroprotective effect. The aim of the present study was to assess the effect of gabapentin in patients with supratentorial brain tumours undergoing craniotomy under general anaesthesia. Methods: A radial arterial line, central venous line and ventriculostomy catheters were inserted before surgery. Anaesthesia was induced with thiopental, fentanyl and atracurium and maintained with sevoflurane, fentanyl and atracurium infusion. The study included 160 patients classified randomly into two groups: Group G: The patients received gabapentin capsules $1200 \mathrm{mg}$ orally $2 \mathrm{~h}$ before surgery. Group C: The patients received placebo capsules. Results: The heart rate, mean arterial blood pressure and intracranial pressure decreased significantly with gabapentin as compared to the control group $(P<0.05)$. The dose of fentanyl and end-tidal sevoflurane was lower with gabapentin than the control group $(P<0.05)$. The urine output was higher in the gabapentin group than the control group $(P<0.05)$. The Glasgow coma scale score was better in the gabapentin group as compared to the control group $(P<0.05)$. The incidence of nausea and vomiting was lower in the gabapentin group as compared to the control group $(P<0.05)$. Conclusions: Pre-operative administration of gabapentin in patients undergoing craniotomy under general anaesthesia minimised the fluctuations in haemodynamics, reduced the requirements for sevoflurane and fentanyl, decreased intracranial pressure and improved the outcomes. There were some side effects associated with gabapentin such as hypotension and bradycardia.
\end{abstract}

Key words: Gabapentin, Glasgow coma scale score, haemodynamics, intracranial pressure, supratentorial craniotomy

\section{INTRODUCTION}

The intense surgical stimuli associated with craniotomy frequently induce sympathetic activation and marked changes in systemic arterial pressure, cerebrospinal fluid

Department of Anaesthesia, Faculty of Medicine, Cairo University, Giza, Egypt

Address for correspondence:

Dr. Rabie Soliman, Department of Anaesthesia,

Faculty of Medicine, Cairo University, Giza, Egypt.

E-mail: rabiesoliman@hotmail.com

\begin{tabular}{|l|l|}
\hline \multicolumn{2}{|c|}{ Access this article online } \\
\hline Quick Response Code: & Website: \\
\hline & www.jnaccjournal.org \\
\hline & \\
\hline
\end{tabular}

and intracranial pressure. Cerebrovascular responses may result in elevated intracranial pressure and reduction in cerebral perfusion pressure, especially in patients with impaired auto-regulation and compromised cerebral compliance. Perioperative hypertension in neurosurgical patients is associated with intracranial bleeding and prolonged hospital stay. ${ }^{[1]}$ Thus, the prevention and control of the haemodynamic responses to nociceptive stimuli are of utmost importance to preserve cerebral homoeostasis in neurosurgical patients. ${ }^{[2,3]}$

This is an open access article distributed under the terms of the Creative Commons Attribution-NonCommercial-ShareAlike 3.0 License, which allows others to remix, tweak, and build upon the work non-commercially, as long as the author is credited and the new creations are licensed under the identical terms.

For reprints contact: reprints@medknow.com

How to cite this article: Soliman R, Zohry G. Assessment of the role of gabapentin in patients with supratentorial tumours undergoing craniotomy under general anaesthesia: A double-blind randomised study. J Neuroanaesthesiol Crit Care 2017;4:147-54. 
Gabapentin is structurally related to the neurotransmitter gamma-aminobutyric acid (GABA) ${ }^{[3]}$ The mechanism of action of gabapentin on the central nervous system differs from that of GABA. Gabapentin acts by decreasing the synthesis of the neurotransmitter glutamate ${ }^{[4]}$ and binding to the alpha 2 delta subunits of voltage-dependent calcium channels,,$^{[5]}$ thus acting in the manner similar to calcium channel blockers. ${ }^{[6]}$ The previous studies showed that gabapentin attenuates the haemodynamics ${ }^{[7-12]}$ and neuroendocrine response to laryngoscopy and tracheal intubation..$^{[13]}$ Gabapentin has anticonvulsant, anti-nociceptive, anxiolytic and neuroprotective activities. ${ }^{[14-17]}$ The aim of the present study was to assess the effects of gabapentin in patients with supratentorial brain tumours undergoing craniotomy under general anaesthesia.

\section{MATERIALS AND METHODS}

\section{Patients}

The study was done after obtaining informed consent and approval from the Local Ethics and Research Committee, in Kasr El-Aini Hospital, Cairo University, Egypt (2014-2016). The study was double-blind randomized and included 160 patients with computed tomography scanning proof of supratentorial brain tumour and scheduled for elective craniotomy under general anaesthesia. Exclusion criteria included patients with cardiac, renal or psychiatric diseases or pre-operative treatment with beta or calcium channel blockers, known allergy to gabapentin or emergency surgery (with midline shift). All patients were admitted to the Neurosurgical Intensive Care Unit (ICU) one night before surgery. The patients were classified randomly (by simple randomization through a process of coin-tossing) into two groups (each $=80$ ), and the study medication was given blindly by the anaesthetic staff nurse: Group G: The patients received gabapentin capsules $1200 \mathrm{mg}$ (Neurontin: capsules 400 mg, Pfizer, Goedecke, GmbH, Germany) orally $2 \mathrm{~h}$ (in the neurosurgical ICU) before surgery. Gabapentin $1200 \mathrm{mg}$ was used as it is the most effective pre-operative dose for pre-medication. ${ }^{[18-21]}$ Group C: The patients received placebo capsules (the placebo capsules were filled with sugar after the evacuation of the capsule of gabapentin).

\section{Anaesthetic technique}

In the neurosurgical ICU under local anaesthesia, radial arterial catheter and central venous catheter in the sub-clavian vein were inserted for continuous monitoring of the heart rate, arterial blood pressure and central venous pressure. The ventriculostomy catheter was inserted under local anaesthesia by a neurosurgeon through a burr hole into the lateral ventricle of the brain for monitoring the intracranial pressure. In the operating room after fixing the monitors, the patients were pre-oxygenated, and then, intravenous thiopental $(3-5 \mathrm{mg} / \mathrm{kg})$ was given followed by fentanyl ( $3-5 \mathrm{mcg} / \mathrm{kg}$ ) and atracurium $0.5 \mathrm{mg} / \mathrm{kg}$ as a bolus dose over 30 seconds, while controlled hyperventilation with $100 \%$ oxygen was started. Before the intubation, an additional bolus of thiopental $(2-3 \mathrm{mg} / \mathrm{kg})$ was given. After induction, controlled mechanical ventilation was adjusted to maintain $\mathrm{PaCO}_{2}$ between 30 and $35 \mathrm{mmHg}$. The anaesthesia was maintained with sevoflurane $0.5 \%-3 \%$, atracurium infusion of $0.5 \mathrm{mg} / \mathrm{kg} / \mathrm{h}$ and fentanyl infusion $(1 \mathrm{mcg} / \mathrm{kg} / \mathrm{h})$. Bolus doses of fentanyl $(1-2 \mathrm{mcg} / \mathrm{kg})$ were given to control the increased heart rate and systemic hypertension during surgery according to the need. Fluids resuscitation and maintenance were provided with glucose free iso-osmolar crystalloid solutions $2-3 \mathrm{ml} / \mathrm{kg} / \mathrm{h}$ and replacement of blood loss and urine output. Drugs such as corticosteroids, furosemide $(1-2 \mathrm{mg} / \mathrm{kg})$ and mannitol $(1 \mathrm{~g} / \mathrm{kg})$ were given according to the need. Esmolol was added if there was intraoperative tachycardia or hypertension before opening the dura mater. Nitroglycerine was added if needed to control intraoperative hypertension after opening the dura mater. Patients with a heart rate below $50 \mathrm{bpm}$ were managed with a small dose of atropine $0.02 \mathrm{mg} / \mathrm{kg}$. If the mean arterial blood pressure decreased below $60 \mathrm{mmHg}$, it was managed with fluids and a small dose of ephedrine (5-10 mg) if needed. At the end of surgery, all patients were transferred to the neurosurgical ICU for monitoring before extubated smoothly.

\section{Monitoring}

The monitoring included heart rate, mean arterial blood pressure, central venous pressure, arterial oxygen saturation, end-tidal carbon dioxide, core temperature from nasopharyngeal probe and intracranial pressure every $5 \mathrm{~min}$. The end-tidal concentration of sevoflurane, total dose of fentanyl, urine output and arterial blood gases were recorded. Neurological assessment was done for all patients by Glasgow coma scale before induction of anaesthesia and after $2 \mathrm{~h}$ of extubation. The incidence of intraoperative awareness was evaluated after $2 \mathrm{~h}$ of extubation.

Data of the patients were collected at the following time points, T0: before administration of the study medication or placebo; T1: 5 min after induction of anaesthesia, T2: 30 min after induction; T3: $1 \mathrm{~h}$ after induction; T4: at the end of surgery; T5: on admission to the ICU; T6: before extubation and T7: $2 \mathrm{~h}$ after extubation.

\section{Outcomes}

The primary outcome was the stability of the haemodynamic status of the patients during surgery. Secondary outcomes were intracranial changes, total fentanyl dose, end-tidal sevoflurane concentration, 
neurological outcome. The safety of the gabapentin was assessed by the occurrence of any adverse events.

\section{Sample size calculation}

Power analysis was performed using Chi-square $\left(\chi^{2}\right)$ test for independent samples on frequency of haemodynamic instability intraoperatively because it was the main outcome variable in the present study. A pilot study was done before starting this study because there are no available data in literature for the role of gabapentin in patients with supratentorial brain tumours undergoing craniotomy under general anaesthesia. The results of the pilot study showed the incidence of haemodynamic instability was $13.2 \%$ in the gabapentin group and $31.5 \%$ in the control group. Taking power of 0.8 and alpha error of 0.05 , a minimum sample size of 80 patients was calculated for each group.

\section{Statistical analysis}

Data were statistically described in terms of range, mean \pm standard deviation, frequencies (number of cases) and relative frequencies (percentages) when appropriate. Comparison of quantitative variables between the study groups was done using Mann-Whitney U-test for independent samples. For comparing categorical data, Chi-square test was performed. Fisher's exact test was used instead when the expected frequency is <5. A p-value less than 0.05 was considered as statistically significant. All statistical calculations were done using computer programs, Microsoft Excel version 7 (Microsoft Corporation, NY, USA) and SPSS (Statistical Package for the Social Science; SPSS Inc., Chicago, IL, USA) statistical program for Microsoft Windows.

\section{RESULTS}

Figure 1 shows the CONSORT diagram for the flow of participants through each stage of the study. Two patients of each group were excluded from the analysis because of massive bleeding (either intraoperative or post-operative). There was no significant difference regarding the demographic data and pre-operative co-morbidities $(P>0.05)$ [Table 1].

The heart rate decreased "greatly" in patients of Group G compared to the baseline, but in Group C, the heart rate increased slightly compared with baseline and the comparison between the two groups was significant $(P<0.05)$ [Table 2 and Figure 2]. The decrease in heart rate below $50 \mathrm{bpm}$ was in 12 patients of Group $G$ and three patients of Group $C$ and the comparison was significant $(P=0.031)$ [Table 3 ] and managed with incremental doses of atropine $(0.02 \mathrm{mg} / \mathrm{kg})$. There was sinus tachycardia in four patients of Group $G$ and 18 patients of Group $\mathrm{C}$ and the patients were managed by increasing the sevoflurane concentration, bolus doses
Table 1: Preoperative data of patients (mean $\pm S D$, number)

\begin{tabular}{lccc}
\hline Variable & $\begin{array}{c}\text { Group G } \\
(\boldsymbol{n}=78)\end{array}$ & $\begin{array}{c}\text { Group C } \\
(\boldsymbol{n}=78)\end{array}$ & $\boldsymbol{p}$ \\
\hline Age (year) & $43.52 \pm 15.26$ & $45.18 \pm 16.34$ & 0.513 \\
Weight $(\mathrm{kg})$ & $85.63 \pm 12.27$ & $83.18 \pm 13.79$ & 0.242 \\
Gender & & & \\
$\quad$ Male & 49 & 45 & 0.744 \\
Female & 29 & 33 & 0.667 \\
Hypertension & 15 & 12 & 0.525 \\
Diabetes mellitus & 8 & 10 & 0.616 \\
\hline Group G: Gabapentin group, Group C: Control group
\end{tabular}

Table 2: Heart rate changes of patients (mean \pm SD)

\begin{tabular}{lccc}
\hline Timepoints & $\begin{array}{c}\text { Group G } \\
(\boldsymbol{n}=\mathbf{7 8})\end{array}$ & $\begin{array}{c}\text { Group C } \\
(\boldsymbol{n}=\mathbf{7 8})\end{array}$ & $\boldsymbol{p}$ \\
\hline T0 & $91.64 \pm 6.72$ & $90.51 \pm 7.39$ & 0.319 \\
T1 & $87.18 \pm 6.60$ & $90.94 \pm 8.33$ & 0.002 \\
T2 & $82.65 \pm 6.48$ & $89.73 \pm 7.52$ & 0.001 \\
T3 & $80.42 \pm 5.47$ & $87.68 \pm 8.32$ & 0.001 \\
T4 & $78.95 \pm 6.85$ & $85.57 \pm 7.13$ & 0.001 \\
T5 & $79.64 \pm 6.44$ & $86.51 \pm 5.75$ & 0.001 \\
T6 & $80.87 \pm 5.93$ & $86.23 \pm 6.92$ & 0.001 \\
T7 & $80.30 \pm 6.82$ & $87.39 \pm 6.85$ & 0.001 \\
\hline
\end{tabular}

$\mathrm{T} 0=$ Before administration of the study medication,

$\mathrm{T} 1=5$ minutes after induction of anaesthesia, $\mathrm{T} 2=30$ minutes after induction, $\mathrm{T} 3=$ One hour after induction, $\mathrm{T} 4=\mathrm{At}$ the of end surgery, $\mathrm{T} 5=\mathrm{On}$ admission to the ICU, T6=Before extubation and $\mathrm{T} 7=2$ Hours after extubation.

Group G: Gabapentin group, Group C: Control group

of fentanyl (50-100 mcg) or esmolol (incremental doses of $0.5 \mathrm{mg} / \mathrm{kg}$ over $30 \mathrm{~s}$ or infusion $50-200 \mathrm{mcg} / \mathrm{kg} / \mathrm{min}$ if needed).

The mean arterial blood pressure decreased in patients of Group G more than patients of Group C with a significant statistical difference between the two groups $(P<0.05)$ [Table 4 and Figure 3$]$. The mean arterial blood pressure decreased below $60 \mathrm{mmHg}$ in 13 patients of Group $G$ and 4 patients of Group C $(P=0.020)$ and the hypotension was managed with incremental doses ephedrine (5 mg) [Table 3]. Six patients in Group G and 16 patients in Group C suffered from hypertension $(P=0.036)$ and they were managed by increasing the sevoflurane concentration, bolus doses of fentanyl (50-100 mcg) or esmolol, in addition to nitroglycerine infusion after opening of the dura mater [Table 3].

There was no significant difference in the central venous pressure of the patients between the two groups $(P>0.05)$ [Table 5]. The intracranial pressure 


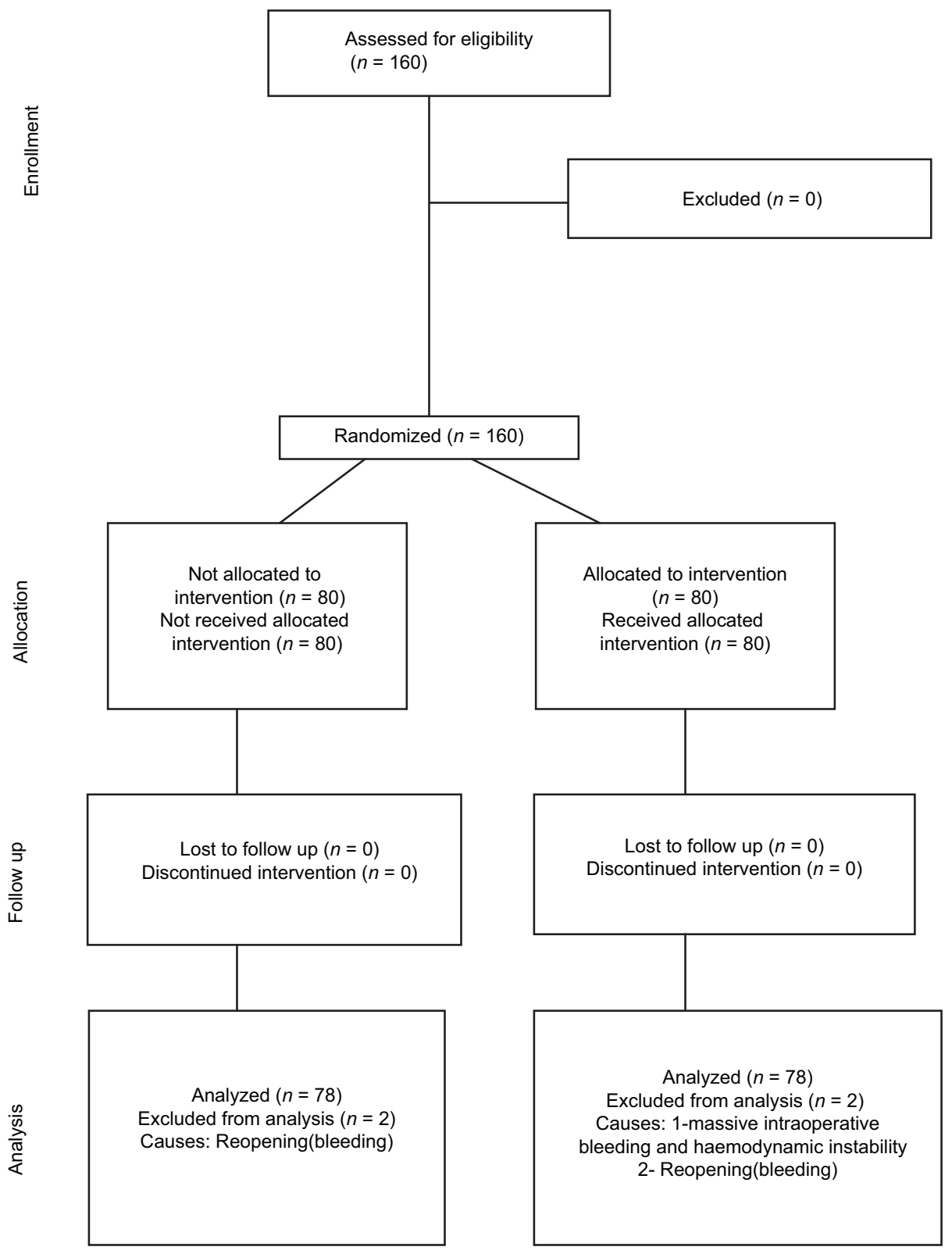

Figure 1: CONSORT diagram for the flow of participants through each stage of the present study

decreased in patients of Group G more than Group C, with a significant difference between the two groups $(P<0.05)$.

Table 6 shows the intra- and post-operative data of patients. There was no difference regarding the temperature, duration of the procedures and types of supratentorial brain tumours $(P>0.05)$. The total fentanyl requirements during the procedures were lower in Group $\mathrm{G}$ than in patients of Group C, with a significant statistical difference between the two groups $(P<0.05)$. The end-tidal sevoflurane concentration was lower in Group $G$ than in patients of Group C, with a significant difference between the two groups $(P<0.05)$. The urine output was higher in Group G more than the Group C, with a significant difference between the two groups $(P<0.001)$. The recovery time (time from the end of anaesthesia to the time of opening the eyes spontaneously or the response to verbal commands) between the two groups was shorter in Group $\mathrm{G}(P<0.001)$. The extubation time (duration from the end of anaesthesia until the patients become fully awake and removal of endotracheal tube) was shorter in patients of Group $G$ than Group C $(P<0.001)$. The incidence of nausea and vomiting was lower in Group G compared to the Group C $(P=0.009)$; therefore, the requirement for antiemetic medications (metoclopramide and 
Table 3: Intracranial pressure changes of patients (mean $\pm \mathrm{SD})$

\begin{tabular}{lccc}
\hline Timepoints & $\begin{array}{c}\text { Group G } \\
(\boldsymbol{n}=\mathbf{7 8 )}\end{array}$ & $\begin{array}{c}\text { Group C } \\
(\boldsymbol{n}=\mathbf{7 8})\end{array}$ & $\boldsymbol{p}$ \\
\hline T0 & $22.53 \pm 3.25$ & $21.82 \pm 3.69$ & 0.204 \\
T1 & $21.65 \pm 2.90$ & $21.63 \pm 3.13$ & 0.967 \\
T2 & $16.35 \pm 1.34$ & $18.88 \pm 2.44$ & 0.011 \\
T3 & $14.80 \pm 1.22$ & $17.92 \pm 2.26$ & 0.001 \\
T4 & $12.22 \pm 1.06$ & $15.38 \pm 1.98$ & 0.001 \\
T5 & $12.56 \pm 1.03$ & $14.76 \pm 1.86$ & 0.001 \\
T6 & $11.92 \pm 0.95$ & $14.58 \pm 1.37$ & 0.001 \\
T7 & $10.54 \pm 0.87$ & $13.29 \pm 1.43$ & 0.001 \\
\hline
\end{tabular}

$\mathrm{T} 0=$ before administration of the study medication,

$T 1=5$ minutes after induction of anaesthesia, $T 2=30$ minutes after induction, $\mathrm{T} 3=$ one hour after induction, $\mathrm{T} 4=$ at the of end surgery, $\mathrm{T} 5=\mathrm{on}$ admission to the ICU, T6=before extubation and T7=2 hours after extubation. Group G: Gabapentin group, Group C: Control group

\section{Table 4: Mean arterial blood pressure of patients (mean \pm SD)}

\begin{tabular}{lccc}
\hline Timepoints & $\begin{array}{c}\text { Group G } \\
(\boldsymbol{n}=78)\end{array}$ & $\begin{array}{c}\text { Group C } \\
(\boldsymbol{n}=78)\end{array}$ & $\boldsymbol{p}$ \\
\hline T0 & $95.45 \pm 8.67$ & $96.62 \pm 7.80$ & 0.377 \\
T1 & $90.59 \pm 5.80$ & $94.87 \pm 6.74$ & 0.001 \\
T2 & $86.64 \pm 5.75$ & $97.42 \pm 6.22$ & 0.001 \\
T3 & $84.53 \pm 6.44$ & $93.86 \pm 5.19$ & 0.001 \\
T4 & $82.60 \pm 5.79$ & $92.90 \pm 6.73$ & 0.001 \\
T5 & $83.58 \pm 4.87$ & $90.43 \pm 5.66$ & 0.001 \\
T6 & $85.49 \pm 5.80$ & $92.64 \pm 5.18$ & 0.001 \\
T7 & $86.56 \pm 5.38$ & $94.74 \pm 6.77$ & 0.001 \\
\hline
\end{tabular}

T0=Before administration of the study medication,

T1 $=5$ minutes after induction of anaesthesia,

T2=30 minutes after induction, T3=One hour after induction, T4=At the of end surgery, $\mathrm{T} 5=\mathrm{O}$ admission to the $\mathrm{ICU}, \mathrm{T} 6=$ Before extubation and T7=The reading 2 hours after extubation. Group G: Gabapentin group,Group C: Control group

Table 5: Central venous pressure changes of patients (mean \pm SD)

\begin{tabular}{lccc}
\hline Timepoints & $\begin{array}{c}\text { Group G } \\
(\boldsymbol{n}=\mathbf{7 8})\end{array}$ & $\begin{array}{c}\text { Group C } \\
(\boldsymbol{n}=\mathbf{7 8})\end{array}$ & $\boldsymbol{p}$ \\
\hline T0 & $13.12 \pm 1.08$ & $13.15 \pm 1.13$ & 0.865 \\
T1 & $11.33 \pm 1.46$ & $11.18 \pm 1.39$ & 0.512 \\
T2 & $11.30 \pm 1.10$ & $11.25 \pm 1.28$ & 0.794 \\
T3 & $10.89 \pm 1.20$ & $11.04 \pm 1.08$ & 0.413 \\
T4 & $10.40 \pm 1.17$ & $10.72 \pm 1.25$ & 0.101 \\
T5 & $9.81 \pm 1.02$ & $9.55 \pm 1.11$ & 0.129 \\
T6 & $9.36 \pm 1.03$ & $9.40 \pm 1.09$ & 0.814 \\
T7 & $9.12 \pm 1.35$ & $9.25 \pm 1.24$ & 0.532 \\
\hline
\end{tabular}

T0=Before administration of the study medication,

$\mathrm{T} 1=5$ minutes after induction of anaesthesia, $\mathrm{T} 2=30$ minutes after induction, T3=One hour after induction, T4=At the of end surgery, T5=On admission to the ICU, T6=Before extubation and T7=2 hours after extubation. Group G:

Gabapentin group, Group C: Control group ondansetron) was lower in Group $G$ than the Group C $(P=0.043, P=0.034$, respectively). GCS at baseline was comparable but it was significantly higher in group $\mathrm{G}$ after surgery with a significant difference between the two groups $(P=0.002)$. There was no intraoperative awareness.

\section{DISCUSSION}

Many articles were reviewed to compare the results of the present study, but there were few studies that assessed only some effects of gabapentin and there were no data about the other effects of gabapentin in patients undergoing craniotomy for supratentorial tumours.

The present study showed that the gabapentin attenuated significantly the haemodynamic responses to laryngoscopy, intubation, Mayfield three-pin head holder application surgical stimulation, during the surgery and extubation in patients undergoing supratentorial surgery. To control the haemodynamic responses in patients of the control group, higher doses of sevoflurane, fentanyl and esmolol were used before the opening of the dura in addition to nitroglycerine after opening of the dura. These findings correlate with the results of Misra et al. ${ }^{[22]}$ They evaluated the effect of $900 \mathrm{mg}$ gabapentin given $2 \mathrm{~h}$ before elective craniotomy in 47 patients, and they found that gabapentin alone abolished the increases in the heart rate and arterial blood pressure after skull pin insertion as compared to placebo or lidocaine infiltration. There were two studies which found that the gabapentin decreased significantly the heart rate and mean arterial blood pressure during and through $10 \mathrm{~min}$ after the intubation, ${ }^{[8,23]}$ and the same result was documented by El Bakry et al., ${ }^{[24]}$ but the study was done on patients undergoing cataract surgery under peribulbar block.

The decrease in heart rate and arterial blood pressure may be as a result of a significant decrease in catecholamine release caused by gabapentin, ${ }^{[13,25]}$ or inhibition of membrane voltage-dependent calcium channels, ${ }^{[5]}$ thus acting as calcium channel blockers. ${ }^{[6,26]}$

The present study showed that the intracranial pressure decreased significantly in the gabapentin group compared to the control group. This may be as a result of the decreased end-tidal sevoflurane and increased urine output with gabapentin group compared to the control group. The dose of fentanyl decreased significantly in Group G in comparison to Group C and this correlates with the result of Türe et al. ${ }^{[21]}$ this correlates with the results of other studies. ${ }^{[21,27,28]}$

The end tidal sevo concentration and propofol dose decreased in group G compared with control group 
Table 6: Intraoperative and postoperative data of patients (data are presented as mean $\pm \mathrm{SD}$, number)

\begin{tabular}{|c|c|c|c|}
\hline variable & Group G $(n=78)$ & Group C $(n=78)$ & $p$ \\
\hline \multicolumn{4}{|l|}{ Heart rate $(\mathrm{bpm})$} \\
\hline$<50$ & 12 & 3 & 0.031 \\
\hline$>100$ & 4 & 18 & 0.002 \\
\hline \multicolumn{4}{|l|}{ MAP (mm Hg) } \\
\hline$<60$ & 13 & 4 & 0.020 \\
\hline$>100$ & 6 & 16 & 0.036 \\
\hline Temperature $\left({ }^{\circ} \mathrm{C}\right)$ & $36.22 \pm 0.36$ & $36.31 \pm 0.42$ & 0.152 \\
\hline Procedure duration (minute) & $243.65 \pm 84.35$ & $240.18 \pm 82.74$ & 0.795 \\
\hline Total fentanyl dose (mcg) & $452.85 \pm 58.10$ & $480.51 \pm 63.46$ & 0.005 \\
\hline End-tidal sevoflurane (\%) & $1.68 \pm 0.68$ & $1.96 \pm 0.72$ & 0.013 \\
\hline Urine output (ml) & $3275.35 \pm 258.40$ & $2893.73 \pm 247.96$ & 0.001 \\
\hline Recovery time (minute) & $27.40 \pm 5.63$ & $38.25 \pm 8.35$ & 0.001 \\
\hline Extubation time (minute) & $36.18 \pm 7.49$ & $49.42 \pm 9.57$ & 0.001 \\
\hline \multicolumn{4}{|l|}{ Nausea and vomiting } \\
\hline Incidence & 12 & 31 & 0.009 \\
\hline Metoclopramide & 10 & 21 & 0.043 \\
\hline Ondansetron & 2 & 10 & 0.034 \\
\hline \multicolumn{4}{|l|}{ Types of brain tumours } \\
\hline Glioma & 27 & 32 & 0.542 \\
\hline Meningioma & 30 & 28 & 0.758 \\
\hline Astrocytoma & 21 & 18 & 0.722 \\
\hline \multicolumn{4}{|l|}{ Glasgow coma scale } \\
\hline T0 & $12.67 \pm 1.82$ & $12.90 \pm 1.57$ & 0.399 \\
\hline $\mathrm{T} 7$ & $13.47 \pm 1.44$ & $12.80 \pm 1.20$ & 0.002 \\
\hline Glasgow coma scale $<8$ & 2 & 8 & 0.049 \\
\hline
\end{tabular}

$\mathrm{MAP}=$ Mean arterial blood pressure, $\mathrm{T} 0=$ The reading before administration of the study medication, $\mathrm{T} 7=\mathrm{The}$ reading 2 hours after extubation.

Group G: Gabapentin group, Group C: Control group

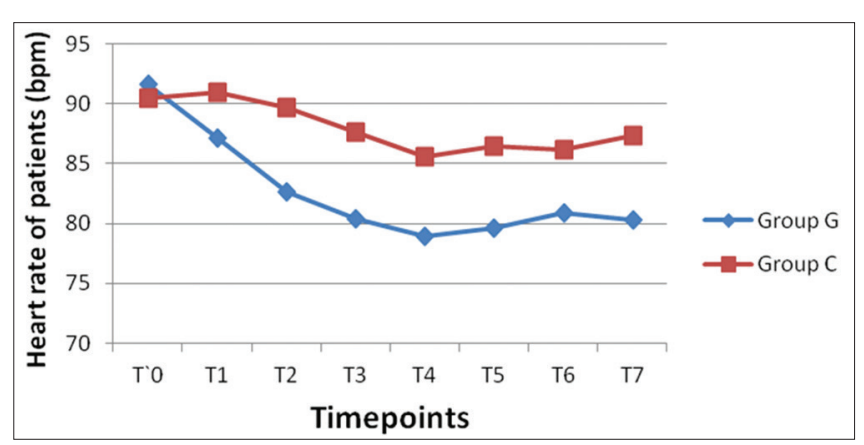

Figure 2: Heart rate changes $\mathrm{T} 0=$ before administration of the study medication, $\mathrm{T} 1=5$ minutes after induction of anaesthesia, $\mathrm{T} 2=30$ minutes after induction, $\mathrm{T} 3=$ one hour after induction, $\mathrm{T} 4=$ at the of end surgery, $\mathrm{T} 5=\mathrm{on}$ admission to the ICU, T6=The reading before extubation and $\mathrm{T} 7=2$ hours after extubation

, and the same has been observed in previous studies also. ${ }^{[20,21]}$

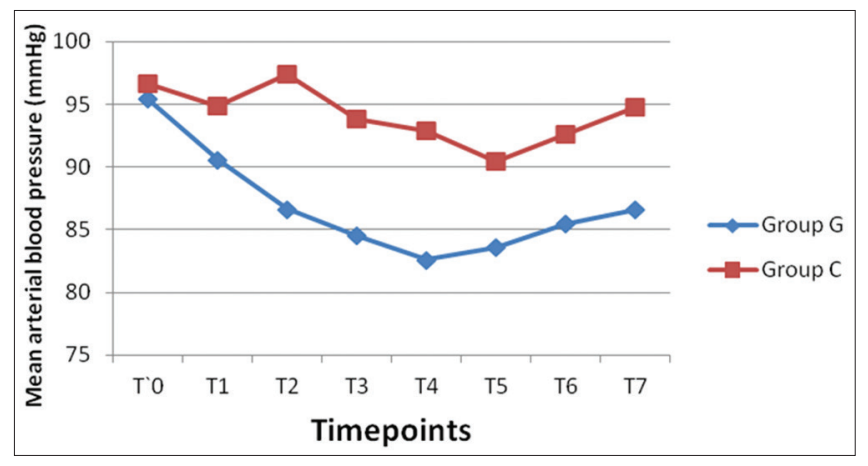

Figure 3: Mean arterial blood pressure changes T0=before administration of the study medication, T1=5 minutes after induction of anaesthesia, T2=30 minutes after induction, T3=one hour after induction, $\mathrm{T} 4=$ at the of end surgery, $\mathrm{T} 5=\mathrm{on}$ admission to the ICU, T6=before extubation and T7=The reading 2 hours after extubation

However, Prabhakar et al. ${ }^{[29]}$ reported that there was no effect of gabapentin on the anaesthetic dose compared 
to placebo, but this may be related to the used dose of gabapentin as they used $800 \mathrm{mg}$; and in the present study, it is $1200 \mathrm{mg}$.

The recovery and extubation times were shorter in the gabapentin group compared to Group $C(P<0.05)$ and this may be as a result of the lower doses of sevoflurane and fentanyl used with gabapentin.

The incidence of nausea and vomiting decreased significantly with gabapentin and the requirement for antiemetic drugs decreased compared to the control group. These findings are in agreement with other studies on this benefit of gabapentin. ${ }^{[30-32]}$ The mechanism of gabapentin in the prevention of post-operative nausea and vomiting is unknown, but it may be related to the post-operative analgesic effect or the decreased perioperative narcotics. ${ }^{[33-36]}$

The urine output increased significantly in the gabapentin group compared to the control group and this may be a result of the decreased catecholamine with gabapentin ${ }^{[13,23]}$ thus inducing renal artery vasodilatation and increasing the urine output.

The Glasgow coma scale was better in Group $G$ than the Group C, and this may be related to the decreased dose of sevoflurane or fentanyl with gabapentin group compared to the control group or as a result of the neuroprotective effects of gabapentin. Gabapentin has been observed to provide brain protection in many experimental studies. ${ }^{\left[{ }^{[3-44]}\right.}$ In spite of the decreased end-tidal sevoflurane concentration with gabapentin, there was no awareness with gabapentin and this may be related to the hypnotic, sedative and amnestic effect of gabapentin. ${ }^{[45-48]}$

\section{CONCLUSION}

Pre-operative administration of gabapentin in patients undergoing craniotomy under general anaesthesia minimised the fluctuations in haemodynamics, reduced the requirements for sevoflurane and fentanyl, decreased intracranial pressure and improved the outcomes. There were few side effects associated with gabapentin such as hypotension. It also decreases the incidence of postoperative nausea and vomiting.

\section{Acknowledgements}

We thank all staff nurses in the operating rooms and neurosurgical ICU for their efforts and performance during the study.

\section{Financial support and sponsorship}

Nil.

\section{Conflicts of interest}

There are no conflicts of interest.

\section{REFERENCES}

1. Basali A, Mascha EJ, Kalfas I, Schubert A. Relation between perioperative hypertension and intracranial hemorrhage after craniotomy. Anesthesiology 2000;93:48-54.

2. Gibson BE, Black S, Maass L, Cucchiara RF. Esmolol for the control of hypertension after neurologic surgery. Clin Pharmacol Ther 1988;44:650-3.

3. Muzzi DA, Black S, Losasso TJ, Cucchiara RF. Labetalol and esmolol in the control of hypertension after intracranial surgery. Anesth Analg 1990;70:68-71.

4. Su TZ, Lunney E, Campbell G, Oxender DL. Transport of gabapentin, a gamma-amino acid drug, by system I alpha-amino acid transporters: A comparative study in astrocytes, synaptosomes, and $\mathrm{CHO}$ cells. J Neurochem 1995;64:2125-31.

5. Pande AC, Pollack MH, Crockatt J, Greiner M, Chouinard G, Lydiard RB, et al. Placebo-controlled study of gabapentin treatment of panic disorder. J Clin Psychopharmacol 2000;20:467-71.

6. Gee NS, Brown JP, Dissanayake VU, Offord J, Thurlow R, Woodruff GN. The novel anticonvulsant drug, gabapentin (Neurontin), binds to the alpha2 delta subunit of a calcium channel. J Biol Chem 1996;271:5768-76.

7. Fassoulaki A, Melemeni A, Paraskeva A, Petropoulos G. Gabapentin attenuates the pressor response to direct laryngoscopy and tracheal intubation. $\mathrm{Br} \mathrm{J}$ Anaesth 2006;96:769-73.

8. Memis D, Turan A, Karamanlioglu B, Seker S, Türe M. Gabapentin reduces cardiovascular responses to laryngoscopy and tracheal intubation. Eur J Anaesthesiol 2006;23:686-90.

9. Kong VK, Irwin MG. Gabapentin: A multimodal perioperative drug? Br J Anaesth 2007;99:775-86.

10. Singhal SK, Kaur K, Arora P. Oral clonidine versus gabapentin as premedicant for obtunding hemodynamic response to laryngoscopy and tracheal intubation. Saudi J Anaesth 2014;8:172-7.

11. Bharti N, Bala I, Narayan V, Singh G. Effect of gabapentin pretreatment on propofol consumption, hemodynamic variables, and postoperative pain relief in breast cancer surgery. Acta Anaesthesiol Taiwan 2013;51:10-3.

12. Bafna U, Goyal VK, Garg A. A comparison of different doses of gabapentin to attenuate the haemodynamic response to laryngoscopy and tracheal intubation in normotensive patients. J Anaesthesiol Clin Pharmacol 2011;27:43-6.

13. Todd RD, McDavid SM, Brindley RL, Jewell ML, Currie KP. Gabapentin inhibits catecholamine release from adrenal chromaffin cells. Anesthesiology 2012;116:1013-24.

14. Taylor CP, Gee NS, Su TZ, Kocsis JD, Welty DF, Brown JP, et al. A summary of mechanistic hypotheses of gabapentin pharmacology. Epilepsy Res 1998;29:233-49.

15. Hunter JC, Gogas KR, Hedley LR, Jacobson LO, Kassotakis L, Thompson J, et al. The effect of novel anti-epileptic drugs in rat experimental models of acute and chronic pain. Eur J Pharmacol 1997;324:153-60.

16. Singh L, Field MJ, Ferris P, Hunter JC, Oles RJ, Williams RG, et al. The antiepileptic agent gabapentin (Neurontin) possesses anxiolytic-like and antinociceptive actions that are reversed by D-serine. Psychopharmacology (Berl) 1996; 127:1-9.

17. Calabresi P, Cupini LM, Centonze D, Pisani F, Bernardi G. Antiepileptic drugs as a possible neuroprotective strategy in brain ischemia. Ann Neurol 2003;53:693-702.

18. Khan ZH, Rahimi M, Makarem J, Khan RH. Optimal dose of pre-incision/post-incision gabapentin for pain relief following lumbar laminectomy: A randomized study. Acta Anaesthesiol Scand 2011;55:306-12. 
19. Ménigaux C, Adam F, Guignard B, Sessler DI, Chauvin M. Preoperative gabapentin decreases anxiety and improves early functional recovery from knee surgery. Anesth Analg 2005;100:1394-9.

20. Doha NM, Rady A, El Azab SR. Preoperative use of gabapentin decreases the anesthetic and analgesic requirements in patients undergoing radical mastectomy. Egypt J Anesth 2010;26:287-91.

21. Türe H, Sayin M, Karlikaya G, Bingol CA, Aykac B, Türe $U$. The analgesic effect of gabapentin as a prophylactic anticonvulsant drug on postcraniotomy pain: A prospective randomized study. Anesth Analg 2009;109:1625-31.

22. Misra S, Koshy T, Unnikrishnan KP, Suneel PR, Chatterjee N. Gabapentin premedication decreases the hemodynamic response to skull pin insertion in patients undergoing craniotomy. J Neurosurg Anesthesiol 2011;23:110-7.

23. Ali AR, El Gohary IM, Ashmawi HS, El-Kerdawy HM, Essa HH. Efficacy of preoperative oral gabapentin in attenuation of neuro-endocrine response to laryngoscopy and endotracheal intubation. J Med Sci 2009;9:24-9.

24. El Bakry AA, Hatim M. The effect of gabapentin premedication on pain and anxiety during cataract surgery under peribulbar block. Egypt J Anaesth 2012;28:43-7.

25. Maneuf YP, Gonzalez MI, Sutton KS, Chung FZ, Pinnock RD, Lee K. Cellular and molecular action of the putative GABA-mimetic, gabapentin. Cell Mol Life Sci 2003;60:742-50.

26. Sarantopoulos C, McCallum B, Kwok WM, Hogan Q. Gabapentin decreases membrane calcium currents in injured as well as in control mammalian primary afferent neurons. Reg Anesth Pain Med 2002;27:47-57.

27. Pandey CK, Sahay S, Gupta D, Ambesh SP, Singh RB, Raza M, et al. Preemptive gabapentin decreases postoperative pain after lumbar discoidectomy. Can J Anaesth 2004;51:986-9.

28. Seib RK, Paul JE. Preoperative gabapentin for postoperative analgesia: A meta-analysis. Can J Anaesth 2006;53:461-9.

29. Prabhakar H, Arora R, Bithal PK, Rath GP, Dash HH. The analgesic effects of preemptive gabapentin in patients undergoing surgery for brachial plexus injury - A preliminary study. J Neurosurg Anesthesiol 2007;19:235-8.

30. Misra S, Parthasarathi G, Vilanilam GC. The effect of gabapentin premedication on postoperative nausea, vomiting, and pain in patients on preoperative dexamethasone undergoing craniotomy for intracranial tumors. J Neurosurg Anesthesiol 2013;25:386-91.

31. Guttuso T Jr., Roscoe J, Griggs J. Effect of gabapentin on nausea induced by chemotherapy in patients with breast cancer. Lancet 2003;361:1703-5.

32. Pandey CK, Priye S, Ambesh SP, Singh S, Singh U, Singh PK. Prophylactic gabapentin for prevention of postoperative nausea and vomiting in patients undergoing laparoscopic cholecystectomy: A randomized, double-blind, placebo-controlled study. J Postgrad Med 2006;52:97-100.

33. Omran AF, Mohamed AE. A randomized study of the effects of gabapentin versus placebo on post-thoracotomy pain and pulmonary function. Egypt J Anaesth 2005;21:277-81.

34. Pandey CK, Priye S, Singh S, Singh U, Singh RB, Singh PK. Preemptive use of gabapentin significantly decreases postoperative pain and rescue analgesic requirements in laparoscopic cholecystectomy. Can J Anaesth 2004;51:358-63.

35. Pandey CK, Navkar DV, Giri PJ, Raza M, Behari S, Singh RB, et al. Evaluation of the optimal preemptive dose of gabapentin for postoperative pain relief after lumbar diskectomy: A randomized, double-blind, placebo-controlled study. J Neurosurg Anesthesiol 2005;17:65-8.

36. Elazzazi H, Atalla R. Evaluation of the optimum preemptive dose of gabapentin and its postoperative morphine-sparing effect after debridement of burned patient. Ain Shams J Anaesthesiol 2014;7:138-42.

37. Rekling JC. Neuroprotective effects of anticonvulsants in rat hippocampal slice cultures exposed to oxygen/glucose deprivation. Neurosci Lett 2003;335:167-70.

38. Rothstein JD, Kuncl RW. Neuroprotective strategies in a model of chronic glutamate-mediated motor neuron toxicity. J Neurochem 1995;65:643-51.

39. Pang $\mathrm{CY}$, Neligan $\mathrm{P}, \mathrm{Xu} \mathrm{H}$, He W, Zhong A, Hopper R, et al. Role of ATP-sensitive $\mathrm{K}+$ channels in ischemic preconditioning of skeletal muscle against infarction. Am J Physiol 1997;273(1 Pt 2):H44-51.

40. Lagrèze WA, Müller-Velten $R$, Feuerstein TJ. The neuroprotective properties of gabapentin-lactam. Graefes Arch Clin Exp Ophthalmol 2001;239:845-9.

41. Lauritzen I, De Weille JR, Lazdunski M. The potassium channel opener(-)-cromakalim prevents glutamate-induced cell death in hippocampal neurons. J Neurochem 1997;69:1570-9.

42. Boll MC, Alcaraz-Zubeldia M, Montes S, Rios C. Free copper, ferroxidase and SOD1 activities, lipid peroxidation and NO $(\mathrm{x})$ content in the CSF. A different marker profile in four neurodegenerative diseases. Neurochem Res 2008;33:1717-23.

43. Baydas G, Sonkaya E, Tuzcu M, Yasar A, Donder E. Novel role for gabapentin in neuroprotection of central nervous system in streptozotocine-induced diabetic rats. Acta Pharmacol Sin 2005;26:417-22.

44. Williams AJ, Bautista CC, Chen RW, Dave JR, Lu XC, Tortella FC, et al. Evaluation of gabapentin and ethosuximide for treatment of acute nonconvulsive seizures following ischemic brain injury in rats. J Pharmacol Exp Ther 2006;318:947-55.

45. Lunn $\mathrm{TH}$, Husted $\mathrm{H}$, Laursen $\mathrm{MB}$, Hansen LT, Kehlet $\mathrm{H}$. Analgesic and sedative effects of perioperative gabapentin in total knee arthroplasty: A randomized, double-blind, placebo-controlled dose-finding study. Pain 2015;156:2438-48.

46. Lo HS, Yang CM, Lo HG, Lee CY, Ting H, Tzang BS. Treatment effects of gabapentin for primary insomnia. Clin Neuropharmacol 2010;33:84-90.

47. Peng PW, Wijeysundera DN, Li CC. Use of gabapentin for perioperative pain control - A meta-analysis. Pain Res Manag 2007; 12:85-92.

48. Chavant F, Favrelière S, Lafay-Chebassier C, Plazanet C, Pérault-Pochat MC. Memory disorders associated with consumption of drugs: Updating through a case/noncase study in the French PharmacoVigilance Database. Br J Clin Pharmacol 2011;72:898-904. 